\author{
불균등 착유 시간간격의 오전· '-후 유량기록을 이용한 1일 \\ 산유량 추정에 관한 연구 \\ 조용민 · 박병호 · 안병석 \\ 농촌진흥청 축산연구소
}

\title{
A Study on Estimating Daily Yield from Morning or Afternoon Milking Records with Unequal Milking Intervals
}

\author{
Y. M. Cho, B. H. Park and B. S. Ahn
}

National Livestock Research Institute, R.D.A.

\begin{abstract}
This study was conducted to evaluate the adequacy of an alternative a.m. - p.m. testing scheme for milk yield in comparison with the official test method based on weighing two milkings within $24 \mathrm{~h}$. A total of 8,309 p.m. milking weights and 6,767 a.m. milking weights from 72 Holstein cows raised at N.L.R.I. were collected between October 2000 and November 2001. Seven statistical models were fitted to the data to derive formulas for estimating daily milk yields from morning or evening yields. In general, use of evening milkings less accurately estimated than did use morning milkings. Although the models do not differ much in the correlations between estimated and true daily milk yields, systematic under- and overestimation of daily milk yields were observed in all models with the exception of model 7, which accounted for heterogeneous variances by parity class, milking interval class, and lactation stage by fitting separate regression formulas within each combination of three factors.
\end{abstract}

(Key words : Daily milk yield, a.m. p.m. Milking interval)

$$
\text { I 서 론 }
$$

현행 젖소의 산유능력 검정은 검정원의 농가 입회하에 $30 \pm 5$ 일 간격으로 1일 2회(오전 및 오후) 측정하여 합산한 유량을 1 일 산유량으로 기록하고 있다. 따라서 검정원 1 인이 담당할 수 있는 검정두수가 제한적이기 때문에 시간, 비용 및 인력 절감을 위해 1 일 1 회 검정착유방 법의 개발의 필요성이 대두되고 있다. 1 회 측 정기록만을 이용할 경우에는 오전 혹은 오후 검정 착유시 차이를 고려한 1 일 산유량 추정을 위해 요인 분석 및 통계적 보정이 필요하다.
오전 혹은 오후의 1 회 측정기록만을 이용한 1 일 산유량 추정시 비유단계, 산차 및 분만계 절 등에 대한 고려가 필요하며(Lee와 Wardrop, 1984), 착유시간 간격이 산유량 비율의 가장 주 요한 요인이었으며, 단순히 오전 혹은 오후 산 유량을 2 배 하였을 때 실제 1 일 산유량보다 평 균 $5 \%$ 정도 과대 또는 과소 추정되는 경향을 보 인다는 연구보고가 있었다(Cassandro 등, 1995). Schaeffer 등(2000)은 상이한 1일 착유횟수에 따른 자료를 이용하여 1 일 산유량 추정시 검정 일 이전 착유와 검정 착유 시간과의 간격에 대 한 고려가 필요하다고 하였다.

Corresponding author : Y. M. Cho, National Livestock Research Institute, R.D.A., Omokcheon-dong, Kwonseon-Gu Suwon, Korea. Tel : 031-290-1607, Fax : 031-290-1602, E-mail : variance@rda.go.kr 
1 회 착유기록에 의한 1 일 산유량 추정의 경 우 DeLorenzo와 Wiggan의 모형(DeLorenzo와 Wiggans, 1986)이 가장 널리 이용되고 있는데, 이 모형은 각각의 착유 간격(MIC; Milking Interval Class)에 대해 개별적인 회귀식을 적합 시키기 위해 착유 간격간(MI; Milking Interval) 에 상이한 평균과 분산을 적용하고, 잔차에서 비유곡선의 효과를 제거하기 위해 비유일수 (DIM; Days In Milk)를 1차 선형회귀로 적합시 켰으나, 산차와 비유단계별 특성이 고려되지 않은 단점이 있다.

따라서 본 연구는 검정 착유중인 우군의 오 전 또는 오후 산유기록을 이용하여 산차, 비유 단계 및 검정착유 시간간격을 고려한 정확한 1 일 산유량 추정을 위해 실시하였다. 이를 통해 1 일 검정입회 횟수를 오전 또는 오후 1 회로 줄 임으로써 검정절차 실시에 유연성을 부여하여 농가의 착유 일정에 주는 부담을 완화하고 두 당 검정비용을 절감하는 효과를 거둘 수 있을 것으로 기대된다.

\section{재료 및 방법}

1. 분석자료

축산연구소에서 사육하고 있는 착유우 72 두 에서 측정한 8,309 개의 오전 착유기록과 6,767 개의 오후 착유기록을 분석에 이용하였으며, Alfa Laval 사의 ALPRO system에 의해 착유우 개체별로 자동 기록된 착유시간에 근거하여, 착유시간 간격을 산출하였으며, 착유 간격 시 간그룹은 30 분 간격으로 오전 및 오후 각각 4 개의 그룹으로 나누었다. 이는 착유시간에 대 한 정보로서 이용하는 현장 기록의 실효성에 따라 Liu 등(2000)이 제시한 방법에 따른 것이 다.

Table 1은 분석에 이용한 착유기록 자료의 기초 통계량에 대한 것이다. 착유시간 간격 (MIC; Milk Interval Class) 간에 유량 평균이 다르고 분산이 상이하며, 1산차에 비해 이후 산차의 기록들은 평균이 높고 분산이 더욱 커

Table 1. Descriptions of first(in the first row) and later(in the second row) parity data from the alternate milking testing schemes

\begin{tabular}{|c|c|c|c|c|c|c|c|c|c|}
\hline \multirow[t]{2}{*}{ Item $^{1)}$} & & \multicolumn{2}{|c|}{$\begin{aligned} & <12.5 \mathrm{~h}^{2)} \\
\geq & 11.5 \mathrm{~h}^{3)}\end{aligned}$} & \multicolumn{2}{|c|}{$\begin{array}{l}12.5 \sim 13.0 \mathrm{~h} \\
11.0 \sim 11.5 \mathrm{~h}\end{array}$} & \multicolumn{2}{|c|}{$\begin{array}{l}13.0 \sim 13.5 \mathrm{~h} \\
10.5 \sim 11.0 \mathrm{~h}\end{array}$} & \multicolumn{2}{|c|}{$\begin{array}{l}\geq 13.5 \mathrm{~h} \\
<10.5 \mathrm{~h}\end{array}$} \\
\hline & & $\mu$ & $\sigma^{2}$ & $\mu$ & $\sigma^{2}$ & $\mu$ & $\sigma^{2}$ & $\mu$ & $\sigma^{2}$ \\
\hline \multirow[t]{4}{*}{$\mathrm{AM}$} & No. records & \multicolumn{2}{|c|}{1,248} & \multicolumn{2}{|c|}{958} & \multicolumn{2}{|c|}{1,395} & \multicolumn{2}{|c|}{264} \\
\hline & & \multicolumn{2}{|c|}{979} & \multicolumn{2}{|c|}{834} & \multicolumn{2}{|c|}{898} & \multicolumn{2}{|c|}{191} \\
\hline & Milk (kg) & 11.1 & 10.9 & 11.9 & 14.6 & 11.3 & 14.5 & 11.8 & 13.7 \\
\hline & & 12.0 & 20.4 & 12.4 & 17.2 & 12.2 & 19.8 & 12.5 & 18.9 \\
\hline \multirow[t]{4}{*}{ PM } & No. records & \multicolumn{2}{|c|}{244} & \multicolumn{2}{|c|}{1,675} & \multicolumn{2}{|c|}{1,281} & \multicolumn{2}{|c|}{1,521} \\
\hline & & \multicolumn{2}{|c|}{158} & \multicolumn{2}{|c|}{1,127} & \multicolumn{2}{|c|}{1,103} & \multicolumn{2}{|c|}{1,200} \\
\hline & Milk (kg) & 9.3 & 9.9 & 9.4 & 11.2 & 10.9 & 12.2 & 10.9 & 11.6 \\
\hline & & 9.6 & 12.4 & 10.2 & 13.9 & 11.1 & 13.8 & 11.7 & 19.2 \\
\hline \multirow[t]{5}{*}{ DMY } & No. records & \multicolumn{8}{|c|}{4,721} \\
\hline & & \multicolumn{8}{|c|}{3,588} \\
\hline & & \multicolumn{4}{|c|}{$\mu$} & \multicolumn{4}{|c|}{$\sigma^{2}$} \\
\hline & Milk (kg) & \multicolumn{4}{|c|}{21.8} & \multicolumn{4}{|c|}{49.5} \\
\hline & & \multicolumn{4}{|c|}{23.3} & \multicolumn{4}{|c|}{67.9} \\
\hline
\end{tabular}

\footnotetext{
1) $\mathrm{AM}=$ a.m. milking, $\mathrm{PM}=$ p.m. milking, $\mathrm{DMY}=$ daily milking.

2) Length of preceding milking interval in hours for morning milking.

3) Length of preceding milking interval in hours for evening milking.
} 
지고 오후 착유(PM) 보다는 오전 착유(AM) 기 록의 평균이 높고 분산이 큰 것으로 나타났다. 따라서 이와 같은 효과를 고려하지 않는 통계 모형은 1 일 유 생산량 추정시 편의(bias)를 발 생시킬 것으로 보이며, Liu 등(2000)이 제시한 바와 같이 MIC, 산차 및 착유시기에 따른 이 분산성(heterogeneous variance)의 고려가 필요할 것으로 판단된다.

Table 2에는 유 생산량에 대한 오전(AM), 오 후(PM) 및 1 일 생산량(DMY)의 상관을 표시하 였다. 오후 유량이 오전 유량보다는 1일 생산 량과 낮은 상관을 보여주고 있으며 1산차에 비 해 이후 산차가 1 일 생산량과 약간 높은 상관 을 보이는 것으로 나타났다. 이는 Liu 등(2000) 이 산차 구분없이 추정한 상관정도 및 순서와 거의 일치하는 결과였다.

Table 2. Correlations among morning, evening and daily milking records by parity

\begin{tabular}{lccc}
\hline Parity & AM-PM $^{1)}$ & AM-DMY & PM-DMY \\
\hline \hline First & 0.914 & 0.980 & 0.977 \\
Later & 0.936 & 0.985 & 0.982 \\
Pooled & 0.926 & 0.983 & 0.980 \\
\hline
\end{tabular}

${ }^{1)} \mathrm{AM}=$ a.m. $\quad$ milking, $\quad \mathrm{PM}=\mathrm{p} . \mathrm{m} . \quad$ milking, $\quad \mathrm{DMY}=$ daily milking.

\section{2. 유 생산량 추정을 위한 통계적 모형}

1 일 1 회 검정기록에 의한 부분 산유량 $\left(y_{A T}\right)$ 을 이용하여 1 일 유 생산량 $\left(y_{A 4}\right)$ 을 추정하는 통 계모형은 몇 가지가 제안되어 있다(Cassandro, 1995; DeLorenzo와 Wiggans, 1986; Everett와 Wadell, 1970; Lee와 Wardrop, 1984). 본 연구에 서는 모형간의 정확성 비교를 위해 7가지 모형 을 이용하였으며, 이들 모형들은 각국의 기관 에서 사용된 적이 있거나 현재 이용하고 있는 모형들로서 1 일 유 생산량 추정을 위한 모형들 에 대한 검증을 통해 장단점을 파악하는 것은 궁극적으로 검정일 모형에 의한 유전능력평가 의 목적을 위해 필요할 것으로 사료된다.
Model 1. DeLorenzo의 모형

$$
y_{A 4}^{[i]}=b_{1}^{[i]} y_{A T}^{[i]}
$$

Model 1은 비유일수(DIM)를 고려하지 않는 DeLorenzo의 Wiggan의 모형(1986)으로 착유 간 격 시간(MIC)에 따라 개별적인 회귀식을 적용 함으로써 각 $\mathrm{MIC}$ 에서의 산유량의 상이한 평균 과 분산을 모형화한 것이다. DeLorenzo의 모형 은 1 일 산유량 $\left(y_{A 4}\right)$ 에 대한 1 회 기록 $\left(y_{A T}\right)$ 의 비율간의 상관을 고려하기 위해 종속변수로 1 일 산유량을 그대로 쓴 것이 아니라 1회 기록 에 대한 1 일 전체 유량의 비율을 이용하였으 나, 본 연구에 이용한 자료에 의한 분석 결과 추정오차가 크게 나타나서 결과 요약에서는 제 외하였으며 1 일 산유량 기록을 직접 이용한 분 석 결과를 제시하였다.

Model 2. 단순 확장 모형 (Doubling Method)

$$
y_{A 4}=2 y_{A T}
$$

이 모형은 1 일 생산량 $\left(y_{A 4}\right)$ 이 오전 또는 오 후 착유량 $\left(y_{A T}\right)$ 평균의 2 배라는 가정에 의한 것이다. 따라서 1 일 유량으로 자료를 변환하는 데 추가적인 정보가 전혀 필요하지 않은 방법 이다.

Model 3. 단순 회귀 모형

$$
y_{\mathrm{A} 4}=b_{0}+b_{1} y_{\mathrm{A} T}
$$

1 일 생산량 $\left(y_{A 4}\right)$ 을 오전 혹은 오후 생산 기 록 $\left(y_{A T}\right)$ 에 회귀하여 보정계수를 추정하는 방 법으로, 전체 자료에 대해 하나의 회귀공식만 을 적합시킨 방법이다.

Model 4. 착유 간격(MI)을 추가한 단순 회귀 모형

$$
y_{A 4}=b_{0}+b_{1} y_{A T}+b_{2} M I
$$

Model 3와 비교하여 착유 간격(MI)에 대한 회귀계수가 모형에 추가되었다. 따라서 1 일 산 유량에 대한 $\mathrm{MI}$ 의 평균 효과가 모형에 고려되 었다. 
Model 5. 착유 간격 계급별(MIC) 개별 회귀 모형

$y_{A 4}^{[i]}=b_{0}^{[i]}+b_{1}^{[i]} y_{A T}^{[i]}$

부분적인 생산량 $\left(y_{A T}\right)$ 또는 1 일 전체 생산 량 $\left(y_{A 4}\right)$ 의 평균과 분산이 각기 다른 점을 고 려하기 위해 착유 간격을 오전 기록과 오후 기 록에 대해 각각 4 개의 계급(MIC)으로 나눠 개 별적인 회귀식을 추정하는 방법이다. Model 5 는 모든 $\mathrm{MIC}$ 에 대한 절편 $\left(b_{0}^{[i]}\right)$ 을 0 으로 놓으 면 Model 1과 동일한 회귀 모형이 된다. Model 5는 Model 1 보다는 회귀공식에 대한 제한 가 정을 적게 한 것이다.

Model 6. DeLorenzo와 Wiggan 모형의 변형

$$
y_{A 4}^{[i]}=b_{0}^{[i]}+b_{1}^{[i]} y_{A T}^{[i]}+b_{2}^{[i]}(D I M-158)
$$

Model 5와 유사하게 각각의 MIC에 대해 개 별적인 회귀를 한다. 잔차에서 비유 단계의 효 과를 제거하기 위해 착유 일수(DIM)에 대한 회귀를 추가하였다. DIM에 대한 분기점은 158 로 놓았으며 이는 착유 일수의 중간지점으로 본 것이다.

Model 7. 산차, 착유간격, 비유단계의 조합에 대해 개별 회귀식 추정 모형

$$
y_{A 4}^{[i j k]}=b_{0}^{[i j k]}+b_{1}^{[i j k]} y_{A T}^{[i j k]}
$$

산차와 비유단계별로 부분생산량 $\left(y_{A T}\right)$ 과 1 일 전체 생산량 $\left(y_{A 4}\right)$ 의 평균이 다르고 이분산 성으로 가지므로, 부분 생산기록에 대한 전체 생산량의 회귀계수는 산차와 비유단계별로 개 별적으로 추정한다. 따라서 산차 $\times \mathrm{MIC} \times$ 비유 단계 요인별 조합 수준에 대해 개별적인 회귀 식을 추정하는 방법이다.

\section{3. $\mathrm{AM} / \mathrm{PM}$ 검정기록에 의한 1 일 유 생산량 추정 모형의 정확도}

1일 유 생산량 추정을 위한 a.m.-p.m. 착유 기록 검정방법의 정확도는 다음과 같이 정의할
수 있다(McDaniel, 1969).

$$
\text { Accuracy }=\sigma^{2} /\left(\sigma^{2}+M S E\right)
$$

여기서, $\sigma^{2}$ 는 실제 1 일 유량 $\left(y_{A 4}\right)$ 의 표현형 분 산, 그리고 $M S E$ 는 실제 1 일 유량과 추정 1 일 유량간의 차이의 분산인 예측 오차 분산 (prediction error variance)이다.

\section{III 결과 및 고찰}

\section{1. 모형별 회귀 계수 추정}

\section{(1) Model 1}

오전 착유 기록(AM)과 오후 착유 기록(PM) 에 의한 1 일 산유량 추정을 위해 이전 착유 시 간과의 간격을 4 개의 그룹으로 나눠 개별 회귀 식을 추정하였다(Table 3). 오전 착유 기록(AM) 에 의한 추정이 오후 착유 기록 $(\mathrm{PM})$ 에 의한 추정에 비해 추정 회귀식의 설명력 $\left(R^{2}\right)$ 이 높고 추정치의 오차가 작은 것으로 나타났으며, 1 회 기록에 대한 1 일 유 생산량의 회귀계수, $\hat{b}_{1}^{[i]}$ 는 오전 착유 기록(AM)의 경우 $1.7922 ~ 1.9610$ 으 로 추정되어 전일 오후 착유 이후 시간 간격이 길수록 유 생산량이 많아지고, 오후 착유 기록 (PM)의 경우 $2.0275 \sim 2.2549$ 로 추정되어 1 일 유 생산량의 절반에 못 미치는 것으로 나타나 서, 회귀계수가 2 를 넘는 것으로 추정되었다.

\section{(2) Model 2}

다른 모형들과 달리 이 모형은 착유에 관한 정보를 전혀 이용하지 않고 오전 착유기록 (AM)과 오후 착유기록(PM)에 대해 단순히 2배 하여 1 일 산유량 추정을 추정하는 방법으로, 다 른 모형에 의한 방법들과 달리 회귀계수 추정치 가 없다. Table 4에 표시한 바와 같이 오전 착유 기록(AM)과 오후 착유 기록에 의한 1 일 유 생 산량을 추정하는 경우 오전 착유량이 1 일 유 생 산량에 차지하는 비율이 높은 이유로 인해 실제 유 생산량에 비해 과대 추정되는 경향을 보였으 며, 오후 착유량으로 1 일 유 생산량을 추정하는 경우에는 반대로 실제 유 생산량에 비해 
Table 3. Estimates of regression coefficients and their standard errors from Model 1 for estimating daily milk yields with morning or evening milking ${ }^{1)}$

\begin{tabular}{llcccc}
\hline \multirow{2}{*}{ Item $^{2)}$} & Estimates $^{3)}$ & \multicolumn{4}{c}{ Milking interval class (MIC) } \\
\cline { 3 - 6 } & & $<12.5 \mathrm{~h}^{4)}$ & $12.5 \sim 13.0 \mathrm{~h}$ & $13.0 \sim 13.5 \mathrm{~h}$ & $\geq 13.5 \mathrm{~h}$ \\
\hline \hline $\mathrm{AM}$ & $\hat{b}_{1}^{[i]}$ & $1.9610 \pm 0.0020$ & $1.9023 \pm 0.0023$ & $1.8235 \pm 0.0017$ & $1.7922 \pm 0.0043$ \\
& $R^{2}$ & 0.9976 & 0.9974 & 0.9980 & 0.9974 \\
& $\sqrt{M S E}$ & 1.1596 & 1.2407 & 0.9555 & 1.1583 \\
\hline & & $\geq 11.5 \mathrm{~h}^{5)}$ & $11.0 \sim 11.5 \mathrm{~h}$ & $10.5 \sim 11.0 \mathrm{~h}$ & $<10.5 \mathrm{~h}$ \\
\cline { 3 - 6 } & $\hat{b}_{1}^{[i]}$ & $2.0275 \pm 0.0022$ & $2.1090 \pm 0.0025$ & $2.2004 \pm 0.0023$ & $2.2549 \pm 0.0058$ \\
& $R^{2}$ & 0.9967 & 0.9967 & 0.9969 & 0.9974 \\
& $\sqrt{M S E}$ & 1.1592 & 1.2688 & 1.4056 & 1.3790 \\
\hline
\end{tabular}

${ }^{1)}$ Direct daily milk yield was used as dependent variable.

2) $\mathrm{AM}=$ a.m. milking, $\mathrm{PM}=$ p.m. milking.

${ }^{3)}$ Each regression coefficient and statistic was derived by fitting a separate regression line within each MIC.

${ }^{4)}$ Length of preceding milking interval in hours for morning milking.

${ }^{5)}$ Length of preceding milking interval in hours for evening milking.

Table 4. Means and their standard deviations of differences between true and estimated daily milk yields from Model 2

\begin{tabular}{lcccc}
\hline Item $^{1)}$ & Mean & S.D & Min & Max \\
\hline \hline $\operatorname{Dev}(A M)$ & -1.3142 & 1.5228 & -10.1000 & 17.5000 \\
$\operatorname{Dev}(P M)$ & +1.3142 & 1.5228 & -17.5000 & 10.1000 \\
\hline
\end{tabular}

${ }^{1)} \operatorname{Dev}(\mathrm{AM})=$ True daily milk yields minus estimated daily milk yields from a.m. milking,

$\operatorname{Dev}(\mathrm{PM})=$ True daily milk yields minus estimated daily milk yields from p.m. milking.

과소 추정되는 경향을 보였다. 따라서 오전 착 유 기록이나 오후 착유 기록을 단순히 2 배 한 1 일 유 생산량 추정은 심한 오차를 야기할 것 으로 사료된다.

(3) Model 3

오전 착유 기록(AM)이나 오후 착유 기록 $(\mathrm{PM})$ 을 이용하여 1 일 유 생산량에 대해 단순 회귀한 Model 3의 경우, $R^{2}$ 는 오전 착유 기록 (AM)을 이용한 경우 0.9658로 오후 착유 기록 $(\mathrm{PM})$ 을 이용한 경우의 0.9600 보다 높았으며 $\sqrt{M S E}$ 의 경우에도 각각 1.4080 및 1.5229 로 오전 기록에 의한 1 일 유 생산량 추정이 비교 적 정확한 것으로 나타났다.
Table 5. Estimates of regression coefficients and their standard errors from single regression model $(3,4)$ for estimating daily milk yields with morning or evening milking

\begin{tabular}{cccc}
\hline Item $^{1)}$ & Estimates $^{2)}$ & Model 3 & Model $4^{3 \text { ) }}$ \\
\hline \hline AM & $\hat{b}_{0}$ & $0.3947 \pm 0.0480$ & $19.9135 \pm 0.3613$ \\
& $\hat{b}_{1}$ & $1.8561 \pm 0.0038$ & $1.8611 \pm 0.0034$ \\
& $\hat{b}_{2}$ & - & $-1.5271 \pm 0.0280$ \\
& $R^{2}$ & 0.9658 & 0.9776 \\
& $\sqrt{M S E}$ & 1.4080 & 1.1317 \\
\hline PM & $\hat{b}_{0}$ & $1.2987 \pm 0.0502$ & $19.1575 \pm 0.3400$ \\
& $\hat{b}_{1}$ & $2.0015 \pm 0.0045$ & $2.0423 \pm 0.0040$ \\
& $\hat{b}_{2}$ & - & $-1.6359 \pm 0.0309$ \\
& $R^{2}$ & 0.9600 & 0.9701 \\
& $\sqrt{M S E}$ & 1.5229 & 1.3169 \\
\hline
\end{tabular}

${ }^{1)} \mathrm{AM}=$ a.m. milking, $\mathrm{PM}=$ p.m. milking.

${ }^{2)}$ Each regression coefficient was derived by fitting a single regression line across all MIC.

${ }^{3)}$ Compared with model 3 , an additional regression coefficient $\left(b_{2}\right)$ on $\mathrm{MI}$ is added into model 4 . 


\section{(4) Model 4}

착유 일수를 공변이로 포함한 Model 4에서 착유 일수에 대한 회귀 계수는 오전 착유 기록 $(\mathrm{AM})$ 의 경우 $-1.5271 \pm 0.0280$ 이었으며, 오후 착유 기록 $(\mathrm{PM})$ 에 대해 $-1.6359 \pm 0.0309$ 로 추 정되었는데 모든 회귀계수가 유의성을 가지는 것으로 나타났다 $(p<.01) . R^{2}$ 는 오전 착유 기록 (AM)을 이용한 경우 0.9776로 오후 착유 기록 (PM)을 이용한 경우의 0.9701보다 높았으며, $\sqrt{M S E}$ 의 경우에도 각각 1.1317 및 1.3169 로 오전 기록에 의한 1 일 유 생산량 추정이 비교적 정확한 것으로 나타났다. 그러나, Model 4에 적용한 착유일수에 대한 공변이는 1 차 선형으 로 적용하였으나, 실제 비유 곡선의 경우 비유 초기에는 증가하고 중기 이후에는 감소하는 경 향을 보이는 것으로 보고되어 있으며, 또한 그 변화 추세도 비유 일수의 진행에 따라 상이하 게 나타나므로, 이 모형의 가정은 문제점을 가 지는 것으로 사료된다.

\section{(5) Model 5}

Model 5는 1일 유 생산량 추정시 이전 착유 와의 시간간격을 구분하여 개별 회귀식을 추정
하는 방법으로 Table 6에는 각 착유간격 시간 대(MIC)에 따른 회귀 계수 추정치와 통계량을 표시하였다. 오후 착유 기록(PM)의 경우 회귀 계수가 $1.9556 \sim 2.1784$ 로 추정되어 오전 착유 와의 착유간격이 11.5 시간 이상일 경우 1 일 유 생산량에 대한 오후 착유량이 $50 \%$ 를 넘는 것 으로 나타났다. 이는 앞의 모형들과는 다소 상 이한 결과로 Model 1에서 포함되지 않은 절편 이 모형에 고려된 결과로 사료된다. 즉 실제 오전, 오후 착유중 한 쪽이 이뤄지지 않더라도 실제 1 일 유 생산량이 0 이 될 수 없는 조건이 반영된 것이다. 모형의 $R^{2}$ 와 $\sqrt{M S E}$ 를 비교 할 때 오전 기록에 의한 1 일 유 생산량 추정이 오후 기록에 의한 추정보다 정확한 것으로 나 타났다.

\section{(6) Model 6}

Model 6는 오전 착유 기록(AM)이나 오후 착 유 기록(PM)을 이용하여 1 일 유 생산량 추정 을 위해 Model 5와 유사하게 이전 착유와의 시간 간격(MIC)을 구분하여 각기 개별적인 회 귀식을 추정하되, 착유 일수(DIM)를 158 일에 중간지점으로 기준으로 하여 연속 변수의 공변

Table 6. Estimates of regression coefficients and their standard errors from Model 5 for estimating daily milk yields with morning or evening milking

\begin{tabular}{llcccc}
\hline \multirow{2}{*}{ Item $^{1)}$} & \multirow{2}{*}{ Estimates $^{2)}$} & \multicolumn{4}{c}{ Milking interval class (MIC) } \\
\cline { 3 - 6 } & & $<12.5 \mathrm{~h}^{3)}$ & $12.5 \sim 13.0 \mathrm{~h}$ & $13.0 \sim 13.5 \mathrm{~h}$ & $\geq 13.5 \mathrm{~h}$ \\
\hline \hline $\mathrm{AM}$ & $\hat{b}_{0}^{[i]}$ & $0.3594 \pm 0.0760$ & $0.5124 \pm 0.0934$ & $0.2057 \pm 0.0625$ & $0.0606 \pm 0.1734$ \\
& $\hat{b}_{1}^{[i]}$ & $1.9329 \pm 0.0063$ & $1.8642 \pm 0.0073$ & $1.8078 \pm 0.0051$ & $1.7877 \pm 0.0136$ \\
& $R^{2}$ & 0.9772 & 0.9733 & 0.9824 & 0.9743 \\
& $\sqrt{M S E}$ & 1.1541 & 1.2307 & 0.9934 & 1.1594 \\
\hline \multirow{3}{*}{} & & $\geq 11.5 \mathrm{~h}^{4)}$ & $11.0 \sim 11.5 \mathrm{~h}$ & $10.5 \sim 11.0 \mathrm{~h}$ & $<10.5 \mathrm{~h}$ \\
\cline { 2 - 5 } & $\hat{b}_{0}^{[i]}$ & $0.9034 \pm 0.0788$ & $0.9054 \pm 0.0909$ & $0.9123 \pm 0.0679$ & $0.8092 \pm 0.1707$ \\
& $\hat{b}_{1}^{[i]}$ & $1.9556 \pm 0.0066$ & $2.0346 \pm 0.0079$ & $2.1174 \pm 0.0066$ & $2.1784 \pm 0.0171$ \\
& $R^{2}$ & 0.9696 & 0.9657 & 0.9737 & 0.9760 \\
& $\sqrt{M S E}$ & 1.3471 & 1.3775 & 1.2299 & 1.1293 \\
\hline
\end{tabular}

\footnotetext{
1) $\mathrm{AM}=$ a.m. milking, $\mathrm{PM}=$ p.m. milking.

${ }^{2)}$ Each regression coefficient and statistic was derived by fitting a separate regression line within each MIC.

3) Length of preceding milking interval in hours for morning milking.

${ }^{4)}$ Length of preceding milking interval in hours for evening milking.
} 
Table 7. Estimates of regression coefficients and their standard errors from Model 6(modified DeLorenzo and Wiggan's model) for estimating daily milk yields with morning or evening milking

\begin{tabular}{llcccc}
\hline \multirow{2}{*}{ Item $^{1)}$} & Estimates $^{2)}$ & \multicolumn{4}{c}{ Milking interval class (MIC) } \\
\cline { 3 - 6 } & & $<12.5 \mathrm{~h}^{3)}$ & $12.5 \sim 13.0 \mathrm{~h}$ & $13.0 \sim 13.5 \mathrm{~h}$ & $\geq 13.5 \mathrm{~h}$ \\
\hline \hline $\mathrm{AM}$ & $\hat{b}_{0}^{[i]}$ & $0.7353 \pm 0.1117$ & $1.1533 \pm 0.1323$ & $0.4594 \pm 0.0777$ & $-0.0258 \pm 0.2196$ \\
& $\hat{b}_{1}^{[i]}$ & $1.9115 \pm 0.0078$ & $1.8236 \pm 0.0094$ & $1.7957 \pm 0.0055$ & $1.7915 \pm 0.0149$ \\
& $\hat{b}_{2}^{[i]}$ & $-0.0006 \pm 0.0001$ & $-0.0010 \pm 0.0001$ & $-0.0005 \pm 0.0001$ & $0.0002 \pm 0.0003$ \\
& $R^{2}$ & 0.9774 & 0.9740 & 0.9826 & 0.9744 \\
& $\sqrt{M S E}$ & 1.1490 & 1.2156 & 0.9873 & 1.1602 \\
\hline & & $\geq 11.5 \mathrm{~h}^{4)}$ & $11.0 \sim 11.5 \mathrm{~h}$ & $10.5 \sim 11.0 \mathrm{~h}$ & $<10.5 \mathrm{~h}$ \\
\cline { 2 - 5 } & $\hat{b}_{0}^{[i]}$ & $1.4738 \pm 0.1151$ & $1.4477 \pm 0.1286$ & $0.9013 \pm 0.0862$ & $1.0715 \pm 0.2123$ \\
& $\hat{b}_{1}^{[i]}$ & $1.9221 \pm 0.0082$ & $1.9960 \pm 0.0102$ & $2.1180 \pm 0.0073$ & $2.1644 \pm 0.0183$ \\
& $\hat{b}_{2}^{[i]}$ & $-0.0009 \pm 0.0001$ & $-0.0008 \pm 0.0001$ & $0.0000 \pm 0.0001$ & $-0.0006 \pm 0.0003$ \\
$R^{2}$ & 0.9701 & 0.9662 & 0.9737 & 0.9762 \\
& $\sqrt{M S E}$ & 1.3362 & 1.3678 & 1.2301 & 1.1248 \\
\hline
\end{tabular}

\footnotetext{
${ }^{1)} \mathrm{AM}=$ a.m. milking, $\mathrm{PM}=$ p.m. milking.

${ }^{2)}$ Each regression coefficient and statistic was derived by fitting a separate regression line within each MIC.

${ }^{3)}$ Length of preceding milking interval in hours for morning milking.

${ }^{4)}$ Length of preceding milking interval in hours for evening milking.
}

량으로 모형에 포함시켜 추정한 것이다. 비유 일수(DIM)에 대한 회귀계수는 오전 착유 기록 에 의한 1 일 유생산량 추정시 착유간격이 13.5 시간 이상일 경우 통계적 유의성이 없는 것으 로 나타났으며, 오후 착유 기록에 의한 경우 오전 착유와의 착유간격이 11 시간 이하일 경우 착유 일수(DIM)에 대한 회귀계수에 통계적 유 의성이 없는 것으로 나타났다 $(\mathrm{p}>.05)$.

Model 6는 착유시간 간격(MIC)과 착유 일수 (DIM)를 모형에 고려함으로써 $R^{2}$ 와 $\sqrt{M S E}$ 를 기준으로 한 모형의 적합도는 개선되는 것으로 나타났으나, Model 4의 결과에서 설명한 것처럼 Model 6에서도 158 일을 착유 일수의 중간 지점 으로 적용하였지만, 세밀한 비유 곡선의 추세를 반영하지 못하는 단점을 여전히 가지고 있다.

\section{(7) Model 7}

Model 7은 산차, 착유시간 간격 및 착유일수 에 따른 비유 단계에 대한 각 조합별로 개별
적인 회귀식을 추정하는 방법이다. 본 연구에 서는 산차를 1 산차와 그 이후 산차의 2 개로 구분하고, 착유 시간 간격(MIC)은 앞서 모형 들에서와 같이 오전 오후 각각 4 개의 구간을 구분하였다. 착유 일수에 따른 비유 단계의 설 정은 본 연구에서 이용한 자료의 오전 및 오 후 유 생산량 평균을 착유일의 진행에 따른 차이에 통계적 유의성이 인정된 5단계로 구분 하였다.

따라서 유 생산량 추정을 위한 요인별 조합 은 $\mathrm{AM} / \mathrm{PM}(2) \times$ 산차 $(2) \times$ 착유간격 $(4) \times$ 비유단 계(5) $=80$ 개의 조합으로 각각에 대해 Model 6 에 의한 회귀계수를 추정하였다. 각각의 요인 조합별로 추정한 결과로 오전 및 오후 착유기 록을 이용한 결과는 Table 8 및 9에 표시한 바 와 같다. 일부 요인 조합에 대해 오전 및 오후 착유 기록에 의한 1 일 유 생산량 추정을 위한 회귀 계수는 자료수의 부족으로 인해 유의성이 있는 회귀 추정이 이뤄지지 못하였다. 
Table 8. Estimates of regression coefficients and their standard errors from Model 7 for estimating daily milk yields with morning milking(AM)

\begin{tabular}{|c|c|c|c|c|c|c|}
\hline \multirow{2}{*}{$\begin{array}{l}\text { Lactation } \\
\text { Stage }^{1)}\end{array}$} & \multirow{2}{*}{ Parity $^{2)}$} & \multirow{2}{*}{$\begin{array}{l}\text { Milking interval } \\
\text { class }(\mathrm{MIC})^{3)}\end{array}$} & \multicolumn{4}{|c|}{ Estimates $^{4)}$} \\
\hline & & & $\hat{b}_{0}^{i j k]}$ & $b_{1}^{i j k]}$ & $R^{2}$ & $\sqrt{M S E}$ \\
\hline \multirow[t]{6}{*}{$\overline{\overline{\text { First }}}$} & First & $<12.5 \mathrm{~h}$ & $1.1177 \pm 0.6324$ & $1.8930 \pm 0.0487$ & 0.9680 & 1.0979 \\
\hline & & $12.5 \sim 13.0 \mathrm{~h}$ & $2.2489 \pm 1.2663$ & $1.7769 \pm 0.0916$ & 0.8685 & 2.0855 \\
\hline & & $\begin{array}{c}13.0 \sim 13.5 \mathrm{~h} \\
\geq 13.5 \mathrm{~h}\end{array}$ & $-1.1432 \pm 1.6346$ & $\begin{array}{c}1.9492 \pm 0.1173 \\
N / A^{5)} \\
\end{array}$ & 0.9583 & 0.9235 \\
\hline & Later & $<12.5 \mathrm{~h}$ & $-0.0063 \pm 1.8728$ & $1.9401 \pm 0.1415$ & 0.9691 & 0.9021 \\
\hline & & $12.5 \sim 13.0 \mathrm{~h}$ & $2.3670 \pm 1.1449$ & $1.7293 \pm 0.0824$ & 0.9263 & 1.3193 \\
\hline & & $\begin{array}{c}13.0 \sim 13.5 \mathrm{~h} \\
\geq 13.5 \mathrm{~h}\end{array}$ & $1.4911 \pm 1.5685$ & $\begin{array}{c}1.7502 \pm 0.0873 \\
\text { N/A }\end{array}$ & 0.9549 & 1.2990 \\
\hline \multirow[t]{7}{*}{ Second } & First & $<12.5 \mathrm{~h}$ & $0.9496 \pm 0.7821$ & $1.9184 \pm 0.0559$ & 0.8858 & 1.6679 \\
\hline & & $12.5 \sim 13.0 \mathrm{~h}$ & $2.1644 \pm 0.4424$ & $1.7796 \pm 0.0291$ & 0.9380 & 1.3732 \\
\hline & & $13.0 \sim 13.5 \mathrm{~h}$ & $1.1652 \pm 0.6083$ & $1.1539 \pm 0.4629$ & 0.9621 & 1.2281 \\
\hline & & $\geq 13.5 \mathrm{~h}$ & $4.2960 \pm 3.9497$ & $1.5114 \pm 0.2172$ & 0.8897 & 1.8773 \\
\hline & Later & $<12.5 \mathrm{~h}$ & $-0.0088 \pm 0.9405$ & $1.9558 \pm 0.0528$ & 0.9561 & 1.1011 \\
\hline & & $12.5 \sim 13.0 \mathrm{~h}$ & $4.0063 \pm 0.8497$ & $1.6681 \pm 0.0497$ & 0.8951 & 1.3646 \\
\hline & & $\begin{array}{c}13.0 \sim 13.5 \mathrm{~h} \\
\geq 13.5 \mathrm{~h}\end{array}$ & $9.1259 \pm 1.3452$ & $\begin{array}{c}1.3389 \pm 0.0763 \\
\text { N/A }\end{array}$ & 0.8462 & 1.6285 \\
\hline \multirow[t]{8}{*}{ Third } & First & $<12.5 \mathrm{~h}$ & $1.1096 \pm 0.3448$ & $1.8751 \pm 0.0252$ & 0.9563 & 0.8973 \\
\hline & & $12.5 \sim 13.0 \mathrm{~h}$ & $1.5976 \pm 0.4540$ & $1.7742 \pm 0.0341$ & 0.9135 & 1.3190 \\
\hline & & $13.0 \sim 13.5 \mathrm{~h}$ & $1.1960 \pm 0.3404$ & $1.7291 \pm 0.0261$ & 0.9178 & 1.1186 \\
\hline & & $\geq 13.5 \mathrm{~h}$ & $2.7746 \pm 1.2204$ & $1.5836 \pm 0.0909$ & 0.8169 & 1.2890 \\
\hline & Later & $<12.5 \mathrm{~h}$ & $1.5191 \pm 0.3848$ & $1.8655 \pm 0.0251$ & 0.9262 & 1.7235 \\
\hline & & $12.5 \sim 13.0 \mathrm{~h}$ & $1.3944 \pm 0.4022$ & $1.8081 \pm 0.0265$ & 0.9484 & 1.2680 \\
\hline & & $13.0 \sim 13.5 \mathrm{~h}$ & $0.6174 \pm 0.2014$ & $1.7802 \pm 0.0128$ & 0.9817 & 0.9250 \\
\hline & & $\geq 13.5 \mathrm{~h}$ & $-0.4987 \pm 0.4315$ & $1.8185 \pm 0.0266$ & 0.9845 & 0.8759 \\
\hline \multirow[t]{8}{*}{ Fourth } & First & $<12.5 \mathrm{~h}$ & $1.7299 \pm 0.4836$ & $1.8090 \pm 0.0397$ & 0.9466 & 0.7470 \\
\hline & & $12.5 \sim 13.0 \mathrm{~h}$ & $0.7309 \pm 0.6851$ & $1.8456 \pm 0.0570$ & 0.9713 & 0.7576 \\
\hline & & $13.0 \sim 13.5 \mathrm{~h}$ & $0.6735 \pm 0.3184$ & $1.7565 \pm 0.0314$ & 0.9556 & 0.6555 \\
\hline & & $\geq 13.5 \mathrm{~h}$ & $1.0598 \pm 0.7908$ & $1.7020 \pm 0.0688$ & 0.9593 & 0.9424 \\
\hline & Later & $<12.5 \mathrm{~h}$ & $2.4094 \pm 0.8476$ & $1.7222 \pm 0.0715$ & 0.9634 & 1.0543 \\
\hline & & $12.5 \sim 13.0 \mathrm{~h}$ & $1.1363 \pm 0.3664$ & $1.7609 \pm 0.0310$ & 0.9711 & 1.0071 \\
\hline & & $13.0 \sim 13.5 \mathrm{~h}$ & $0.0602 \pm 0.3182$ & $1.8108 \pm 0.0330$ & 0.9738 & 0.5021 \\
\hline & & $\geq 13.5 \mathrm{~h}$ & $3.3214 \pm 2.6661$ & $1.4521 \pm 0.2669$ & 0.6352 & 1.5016 \\
\hline \multirow[t]{8}{*}{ Later } & First & $<12.5 \mathrm{~h}$ & $0.2693 \pm 0.0991$ & $1.9324 \pm 0.0102$ & 0.9818 & 0.7609 \\
\hline & & $12.5 \sim 13.0 \mathrm{~h}$ & $0.3211 \pm 0.1615$ & $1.8813 \pm 0.0174$ & 0.9705 & 1.0044 \\
\hline & & $13.0 \sim 13.5 \mathrm{~h}$ & $0.1515 \pm 0.0871$ & $1.8054 \pm 0.0078$ & 0.9860 & 0.9227 \\
\hline & & $\geq 13.5 \mathrm{~h}$ & $-0.3112 \pm 0.2914$ & $1.8367 \pm 0.0252$ & 0.9718 & 1.2613 \\
\hline & Later & $<12.5 \mathrm{~h}$ & $0.8635 \pm 0.1574$ & $1.8588 \pm 0.0187$ & 0.9576 & 0.8370 \\
\hline & & $12.5 \sim 13.0 \mathrm{~h}$ & $0.6368 \pm 0.1903$ & $1.8226 \pm 0.0214$ & 0.9591 & 0.7303 \\
\hline & & $13.0 \sim 13.5 \mathrm{~h}$ & $0.9653 \pm 0.1885$ & $1.7116 \pm 0.0210$ & 0.9472 & 0.7268 \\
\hline & & $\geq 13.5 \mathrm{~h}$ & $1.6718 \pm 0.4186$ & $1.5958 \pm 0.0430$ & 0.9412 & 0.7760 \\
\hline
\end{tabular}

\footnotetext{
${ }^{1)}$ Days in milk were divided into first( $(0 \sim 23 \mathrm{~d})$, second( $\left.77 \mathrm{~d}\right)$, third( $\left.\sim 315 \mathrm{~d}\right)$, fourth( $\left.\sim 365 \mathrm{~d}\right)$ and later(365d $\left.<\right)$ lactation stage.

${ }^{2)}$ Parity was divided into first (1) and later $(1<)$ stage.

${ }^{3)}$ Length of preceding milking interval in hours for morning milking.

4) Each regression coefficient and statistic was derived by fitting a separate regression line within each combination of parity, MIC and lactations stage.

5) As few records were available in this class, the estimates were not acceptable.
} 
Table 9. Estimates of regression coefficients and their standard errors from Model 7 for estimating daily milk yields with evening milking(PM)

\begin{tabular}{|c|c|c|c|c|c|c|}
\hline \multirow{2}{*}{$\begin{array}{l}\text { Lactation } \\
\text { Stage }^{1)}\end{array}$} & \multirow{2}{*}{ Parity $^{2)}$} & \multirow{2}{*}{$\begin{array}{l}\text { Milking interval } \\
\text { class (MIC) }{ }^{3)}\end{array}$} & \multicolumn{4}{|c|}{ Estimates $^{4)}$} \\
\hline & & & $\hat{b}_{0}^{[i j k]}$ & $\hat{b}_{1}^{[j i j k]}$ & $R^{2}$ & $\sqrt{M S E}$ \\
\hline \multirow[t]{8}{*}{ First } & \multirow[t]{4}{*}{ 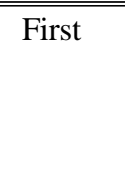 } & $<<10.5 \mathrm{~h}$ & \multicolumn{4}{|c|}{$\mathrm{N} / \mathrm{A}^{5)}$} \\
\hline & & $10.5 \sim 11.0 \mathrm{~h}$ & $-1.9800 \pm 2.2407$ & $2.2807 \pm 0.1915$ & 0.9044 & 1.6314 \\
\hline & & $11.0 \sim 11.5 \mathrm{~h}$ & $0.6146 \pm 0.8127$ & $2.0237 \pm 0.0640$ & 0.9215 & 1.4338 \\
\hline & & $\geq 11.5 \mathrm{~h}$ & $5.5483 \pm 1.0050$ & $1.5438 \pm 0.0739$ & 0.8669 & 2.4148 \\
\hline & \multirow[t]{4}{*}{ Later } & $<10.5 h$ & $-1.4472 \pm 2.7690$ & $2.3437 \pm 0.1795$ & 0.9771 & 0.9745 \\
\hline & & $10.5 \sim 11.0 \mathrm{~h}$ & $1.7584 \pm 1.2727$ & $2.0632 \pm 0.0863$ & 0.9501 & 1.2842 \\
\hline & & $11.0 \sim 11.5 \mathrm{~h}$ & $1.6749 \pm 0.7460$ & $1.9880 \pm 0.0594$ & 0.9573 & 1.0008 \\
\hline & & $\geq 11.5 \mathrm{~h}$ & $3.0077 \pm 2.2248$ & $1.7675 \pm 0.1682$ & 0.8666 & 1.9589 \\
\hline \multirow[t]{8}{*}{ Second } & \multirow[t]{4}{*}{ First } & $<10.5 h$ & $4.3924 \pm 6.4711$ & $1.9832 \pm 0.4688$ & 0.7489 & 2.6093 \\
\hline & & $10.5 \sim 11.0 \mathrm{~h}$ & $1.2149 \pm 0.6147$ & $2.0420 \pm 0.0455$ & 0.9428 & 1.5425 \\
\hline & & $11.0 \sim 11.5 \mathrm{~h}$ & $2.8693 \pm 0.4523$ & $1.8820 \pm 0.0322$ & 0.9119 & 1.7432 \\
\hline & & $\geq 11.5 \mathrm{~h}$ & $5.0508 \pm 0.5832$ & $1.6461 \pm 0.0410$ & 0.8979 & 1.6181 \\
\hline & \multirow[t]{4}{*}{ Later } & $<10.5 h$ & \multicolumn{4}{|c|}{ N/A } \\
\hline & & $10.5 \sim 11.0 \mathrm{~h}$ & $3.4575 \pm 1.4489$ & $1.9121 \pm 0.0958$ & 0.7977 & 2.0881 \\
\hline & & $11.0 \sim 11.5 \mathrm{~h}$ & $3.3531 \pm 0.9510$ & $1.8876 \pm 0.0626$ & 0.8278 & 1.7761 \\
\hline & & $\geq 11.5 \mathrm{~h}$ & $3.5993 \pm 0.8124$ & $1.8412 \pm 0.0475$ & 0.9476 & 1.1681 \\
\hline \multirow[t]{8}{*}{ Third } & \multirow[t]{4}{*}{ First } & $<10.5 \mathrm{~h}$ & $4.2333 \pm 0.8230$ & $1.8487 \pm 0.0774$ & 0.8992 & 1.1245 \\
\hline & & $10.5 \sim 11.0 \mathrm{~h}$ & $3.2752 \pm 0.3257$ & $1.9109 \pm 0.0304$ & 0.8960 & 1.3376 \\
\hline & & $11.0 \sim 11.5 \mathrm{~h}$ & $2.1241 \pm 0.3635$ & $1.9473 \pm 0.0308$ & 0.9134 & 1.3143 \\
\hline & & $\geq 11.5 \mathrm{~h}$ & $1.3491 \pm 0.2997$ & $1.9440 \pm 0.0228$ & 0.9568 & 0.9128 \\
\hline & \multirow[t]{4}{*}{ Later } & $<10.5 \mathrm{~h}$ & $0.4341 \pm 0.9885$ & $2.1914 \pm 0.1109$ & 0.9467 & 0.8709 \\
\hline & & $10.5 \sim 11.0 \mathrm{~h}$ & $0.8810 \pm 0.2236$ & $2.1508 \pm 0.0175$ & 0.9725 & 1.1245 \\
\hline & & $11.0 \sim 11.5 \mathrm{~h}$ & $1.4004 \pm 0.3884$ & $2.0205 \pm 0.0288$ & 0.9379 & 1.3988 \\
\hline & & $\geq 11.5 \mathrm{~h}$ & $2.5933 \pm 0.3463$ & $1.8578 \pm 0.0233$ & 0.9224 & 1.7319 \\
\hline \multirow[t]{8}{*}{ Fourth } & \multirow[t]{4}{*}{ First } & $<10.5 h$ & $1.0797 \pm 0.6942$ & $2.1858 \pm 0.0556$ & 0.9621 & 1.3310 \\
\hline & & $10.5 \sim 11.0 \mathrm{~h}$ & $0.9014 \pm 0.3885$ & $2.1021 \pm 0.0467$ & 0.9227 & 0.9115 \\
\hline & & $11.0 \sim 11.5 \mathrm{~h}$ & $1.4182 \pm 0.7056$ & $1.9783 \pm 0.0662$ & 0.9520 & 0.9015 \\
\hline & & $\geq 11.5 \mathrm{~h}$ & $1.1935 \pm 0.5218$ & $1.9436 \pm 0.0446$ & 0.9368 & 0.8071 \\
\hline & \multirow[t]{4}{*}{ Later } & $<10.5 \mathrm{~h}$ & $2.3515 \pm 0.7099$ & $1.9596 \pm 0.0980$ & 0.9662 & 0.4522 \\
\hline & & $10.5 \sim 11.0 \mathrm{~h}$ & $2.0935 \pm 0.6829$ & $1.9740 \pm 0.0867$ & 0.8356 & 1.2318 \\
\hline & & $11.0 \sim 11.5 \mathrm{~h}$ & $0.0648 \pm 0.3875$ & $2.1618 \pm 0.0383$ & 0.9628 & 1.1805 \\
\hline & & $\geq 11.5 \mathrm{~h}$ & $-0.0426 \pm 0.8928$ & $2.0575 \pm 0.0812$ & 0.9497 & 1.1543 \\
\hline \multirow[t]{8}{*}{ Later } & \multirow[t]{4}{*}{ First } & $<10.5 \mathrm{~h}$ & $0.8905 \pm 0.2344$ & $2.1607 \pm 0.0254$ & 0.9808 & 1.0590 \\
\hline & & $10.5 \sim 11.0 \mathrm{~h}$ & $0.5634 \pm 0.0891$ & $2.1544 \pm 0.0097$ & 0.9821 & 1.0512 \\
\hline & & $11.0 \sim 11.5 \mathrm{~h}$ & $1.0702 \pm 0.1647$ & $1.9721 \pm 0.0195$ & 0.9595 & 1.1272 \\
\hline & & $\geq 11.5 \mathrm{~h}$ & $0.7191 \pm 0.1214$ & $1.9565 \pm 0.0128$ & 0.9665 & 1.0570 \\
\hline & \multirow[t]{4}{*}{ Later } & $<10.5 h$ & $2.0880 \pm 0.5520$ & $1.9789 \pm 0.0766$ & 0.9088 & 0.7499 \\
\hline & & $10.5 \sim 11.0 \mathrm{~h}$ & $1.1385 \pm 0.2131$ & $2.0716 \pm 0.0285$ & 0.9205 & 0.9696 \\
\hline & & $11.0 \sim 11.5 \mathrm{~h}$ & $0.5919 \pm 0.1975$ & $2.0578 \pm 0.0248$ & 0.9444 & 0.9402 \\
\hline & & $\geq 11.5 \mathrm{~h}$ & $0.5100 \pm 0.1427$ & $1.9805 \pm 0.0175$ & 0.9611 & 0.8421 \\
\hline \multicolumn{7}{|c|}{$\begin{array}{l}\left.\left.\left.{ }^{1)} \text { Days in milk were divided into first }(0 \sim 23 \mathrm{~d}) \text {, second( } \sim 77 \mathrm{~d}\right) \text {, third }(\sim 315 \mathrm{~d}) \text {, fourth } \sim 365 \mathrm{~d}\right) \text { and later( } 365 \mathrm{~d}<\right) \text { lacta- } \\
\text { tion stage. } \\
{ }^{2)} \text { Parity was divided into first }(1) \text { and later }(1<) \text { stage. } \\
\text { 3) Length of preceding milking interval in hours for evening milking. } \\
\text { Each regression coefficient and statistic was derived by fitting a separate regression line within each combina- } \\
\text { tion of parity, MIC and lactations stage. }\end{array}$} \\
\hline
\end{tabular}




\section{2. 모형별 적합도(Goodness of fit)}

Table 10 에는 실제 1 일 유 생산량과 추정 1 일 유 생산량간의 상관 $\left(r_{\left.y_{A 4}, \hat{y}_{A 4}\right)}\right)$, 예측 오차 분산의 제곱근 $(\sqrt{M S E})$, 그리고 오전 및 오후 착유기 록을 이용한 1 일 유 생산량 추정치의 표준편차 $\left(\sigma_{\hat{y} A 4}\right)$ 를 표시하였다. $\sqrt{M S E}$ 값이 가장 작고 상관 $\left(r_{\left.y_{A 4}, \hat{y}_{A 4}\right)}\right)$ 이 가장 높은 모형이 자료에 가장 잘 적합되는 모형이며, 유 생산량 추정치의 표 준 편차 $\left(\sigma_{\hat{y}_{A 4}}\right)$ 는 실제 1 일 유 생산량의 표준 편 차 $\left(\sigma_{y_{A 4}}\right)$ 와 가까운 값이어야 하지만 초과해서 는 안된다.

유 생산량 추정을 위한 요인을 추가할수록,
즉 모형이 복잡해질수록 상관정도가 높아져서 Model 7의 경우 가장 높은 상관을 보였지만 모형간의 차이는 작은 편이었다. Model 1 과 Model 2를 제외한 모든 모형에서 실제 1 일 유 생산량의 표준편차 $\left(\sigma_{y_{A 4}}\right)$ 보다 추정 1 일 생산량 의 표준편차 $\left(\sigma_{\hat{y}_{A 4}}\right)$ 가 작게 추정되었다. 실제 1 일 생산량의 표준편차 $\left(\sigma_{y A 4}\right)$ 보다 과대 추정된 Model 1과 Model 2는 1일 유 생산량 추정에 부 적합한 모형임을 의미한다. $\sqrt{M S E}$ 의 수치 비교를 통해 불편 추정의 여부와 함께 분산 추 정치를 구할 수 있다. 따라서 모형의 순위를 매기는데 가장 적절한 기준이 된다. MSE에 근 거하여 Model 7이 가장 우수한 모형으로 나타

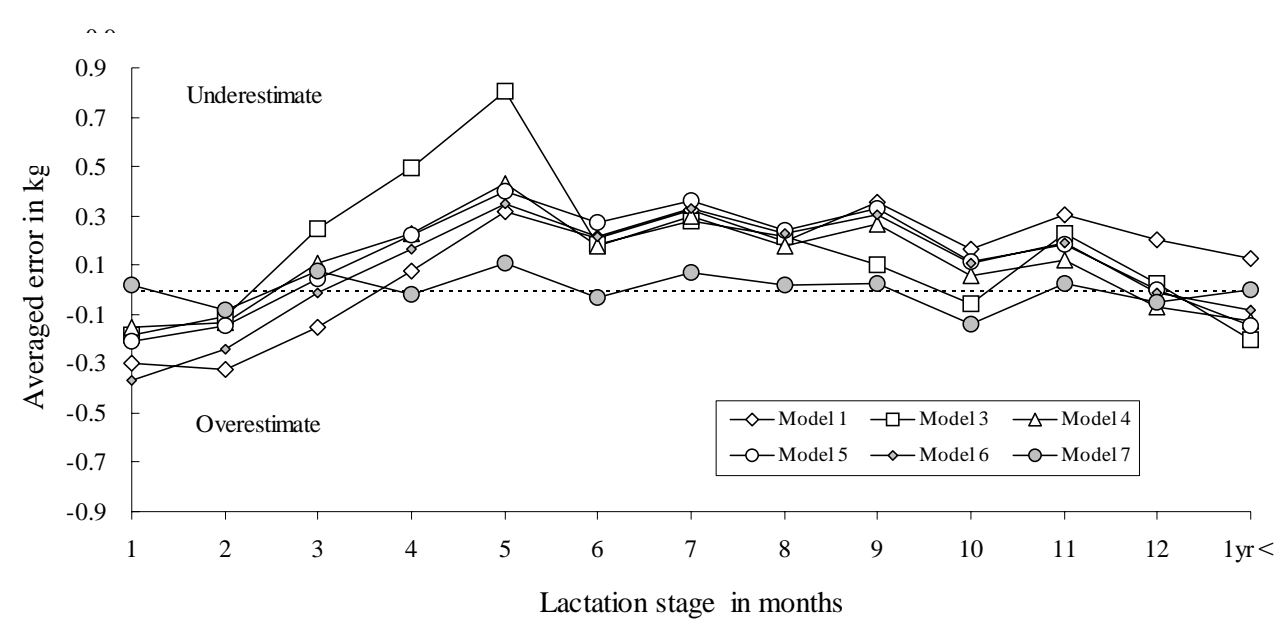

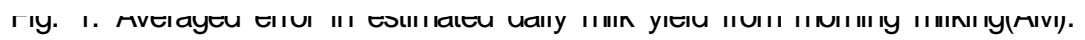

Fig. 2. Averaged error in estimated daily milk yield from evening milking(PM).

Table 10. Correlations between true and estimated daily milk yields, mean squared error and standard deviations of daily yield estimates from morning or evening milking

\begin{tabular}{cccccccc}
\hline \multirow{2}{*}{ Model } & \multicolumn{3}{c}{ AM } & & \multicolumn{3}{c}{ PM } \\
\cline { 2 - 3 } \cline { 6 - 7 } & $\left.r_{y_{A 4}, \hat{y}_{A 4}} 1\right)$ & $\sigma_{\hat{y}_{A 4}}$ & $\sqrt{M S E}$ & & $r_{y_{A 4}, \hat{y}_{A 4}}$ & $\sigma_{\hat{y}_{A 4}}$ & $\sqrt{M S E}$ \\
\hline \hline 1 & 98.687 & $\left.7.6187^{2}\right)$ & 1.2343 & & 98.514 & 7.7796 & 1.3369 \\
2 & 98.276 & 8.0631 & 1.5228 & & 97.980 & 7.4548 & 1.5228 \\
3 & 98.276 & 7.4828 & 1.4080 & 97.980 & 7.4603 & 1.5228 \\
4 & 98.876 & 7.4824 & 1.1316 & 98.493 & 7.4994 & 1.3167 \\
5 & 98.891 & 7.4836 & 1.1238 & & 98.515 & 7.5011 & 1.3073 \\
6 & 98.907 & 7.4848 & 1.1155 & 98.531 & 7.5023 & 1.3003 \\
7 & 98.968 & 7.4894 & 1.0843 & 98.650 & 7.5114 & 1.2468 \\
\hline
\end{tabular}

${ }^{1)}$ Correlations multiplied by 100 .

2) Standard deviations of daily milk yield estimates that are greater than those of true daily milk yield are underlined. 
Table 11. Accuracy of the alternate a.m-p.m. milk testing scheme for estimating daily milk yields

\begin{tabular}{cccccccc}
\hline Item $^{1)}$ & \multicolumn{3}{c}{ AM } & & \multicolumn{3}{c}{ PM } \\
\cline { 7 - 8 } \cline { 6 - 7 } Model & First parity & Later parity & All parity & & First parity & Later parity & All parity \\
\hline \hline 1 & 0.96970 & 0.97857 & 0.97440 & & 0.96486 & 0.97476 & 0.97009 \\
2 & 0.95617 & 0.96623 & 0.96154 & & 0.95617 & 0.96623 & 0.96154 \\
3 & 0.96147 & 0.97167 & 0.96694 & 0.95615 & 0.96624 & 0.96154 \\
4 & 0.97595 & 0.98037 & 0.97839 & & 0.96639 & 0.97513 & 0.97096 \\
5 & 0.96987 & 0.97880 & 0.97461 & & 0.96707 & 0.97524 & 0.97136 \\
6 & 0.97595 & 0.98097 & 0.97873 & 0.96739 & 0.97564 & 0.97166 \\
7 & 0.97685 & 0.98238 & 0.97988 & 0.97039 & 0.97681 & 0.97389 \\
\hline
\end{tabular}

${ }^{1)} \mathrm{AM}=$ a.m. milking, $\mathrm{PM}=$ p.m. milking.

났으며 Model 2가 가장 부적절한 모형으로 판 단된다.

Fig. 1과 2는 각각 오전 착유량과 오후 착유 량으로 추정한 생산량에 대해, $y_{A 4}-\hat{y}_{A 4}$, 즉 평균 추정 오차를 나타낸 것으로, Model 7의 경우 각 비유단계에 대해 개별적으로 회귀공식 을 적합시켰기 때문에 비유단계별 평균 추정오 차가 다른 모형에 비해 가장 작은 것으로 나타 났다. Model 3을 제외한 나머지 모형의 경우, 오전 착유 기록(AM)에 의한 추정은 비유단계 초기에는 추정 1 일 생산량이 과소 추정되었지 만 비유기 후반에 가서는 과대 추정되는 경향 을 보였으며, 오후 착유 기록(PM)에 의한 추정 에서는 반대의 경향을 보이는 것으로 나타났 다. 이는 실제 1 일 생산량에 대한 오전 오후 생산량이 비유단계가 경과함에 따라 변화함을 의미한다. 이러한 추정 오차의 발생 양상은 짭 은 비유기를 제외하고는 305일령 산유량 추정 에 유의한 효과를 미치지는 않을 것으로 사료 되는데, 그 이유는 과대 추정과 과소 추정의 양이 대체적으로 상쇄되는 결과를 가져오기 때 문이다.

\section{3. $\mathrm{AM}-\mathrm{PM}$ 검정 착유계획의 정확도}

1일 생산량 추정에 대한 $\mathrm{AM}-\mathrm{PM}$ 검정 계획 의 정확도를 Table 11에 요약하였다. 오전 착유
기록(AM)과 오후 착유 기록(PM)을 이용한 1 일 유 생산량 추정시 Model 7이 가장 정확도가 높은 것으로 나타났다.

분석에 이용한 모든 모형에서 오전 착유 기 록(AM)을 이용한 1일 유 생산량 추정이 오후 착유 기록 $(\mathrm{PM})$ 에 의한 추정보다 정확도가 모 두 높은 것으로 나타났으며, 모형에 착유 기록 에 관한 정보를 추가할수록 정확도가 높아지 는 것을 나타났다. 산차의 경우 1 산차에 비해 2산차 이상의 산차 기록에 의한 1 일 유 생산 량 추정시 정확도가 다소 높아지는 것으로 나 타났다.

$$
\text { IV 요 약 }
$$

오전(AM) 및 오후(PM)의 단일 착유기록에 의한 유우의 1 일 생산량 추정을 위한 통계적 모형에 대한 연구를 실시하였다. 본 연구에서 조사한 모형들 가운데, Model 7은 각 요인 조 합 구간별로 개별적인 회귀식을 추정함으로써 산차, 착유시간 간격, 비유 단계에 따른 이분산 성을 고려할 수 있기 때문에 평균 오차 제곱 합, 추정치와 실제 1 일 유 생산량간의 상관계 수 및 추정치의 분산을 고려할 때 가장 적합도 가 높은 것으로 사료된다. 오후 착유 기록을 이용한 1 일 유 생산량 추정치는 오전 착유 기 록을 이용한 것보다는 정확도가 낮은 것을 나 
타났으며, Model 7의 경우 1 일 유 생산량 추정 을 위한 제반 요인이 추가되어 정확도가 높일 수 있으면서도 모형이 간단하기 때문에 적용이 간편한 장점이 있다.

\section{$\mathrm{V}$ 인 용 문 헌}

1. Cassandro, M., Carnier, P., Gallo, L., Mantovni, R., Contiero, B., Bittante, G. and Jansen, G. B. 1995. Bias and accuracy of single milk testing schemes to estimate daily and lactation milk yield. J. Dairy Sci. 78:2884-2893.

2. DeLorenzo M. A. and Wiggans, G. R. 1986. Factors for estimating daily yield of milk, fat, and protein from a single milking for herds milked twice a day. J. Dairy Sci. 69:2386-2394.

3. Everett, R. W. and Wadell, L. H. 1970. Sources of variation affecting ratio factors for estimating total daily yield from individual milkings. J. Dairy Sci. 53:1430.

4. Lee, A. J. and Wardrop, J. 1984. Predicting daily milk yield, fat percent, and protein percent from morning or afternoon tests. J. Dairy Sci. 67:351.

5. Liu, Z., Reents, R., Reinhardt, F. and Kuwan, K. 2000. Approaches to Estimating Daily Yield from Single Milk Testing Schemes and Use of a.m.-p.m. Records in Test-Day Model Genetic Evaluation in Dairy Cattle. J. Dairy Sci. 83:2672-2682.

6. McDaniel, B. T. 1969. Accuracy of sampling procedures for estimating lactation yields: a review. J. Dairy Sci. 52:1742.

7. Schaeffer, L. R., Jamrozik, J., Van Drop, R., Kelton, D. F. and Lazenby, D. W. 2000. Estimating daily yields of cows from different milking schemes. Livest. Prod. Sci. 65:219-227.

8. Wiggans, G. W. 1981. Methods to estimate milk and fat yields from a.m./p.m. plans. J. Dairy Sci. 64: 1621.

(접수일자 : 2004. 6. 30./ 채택일자 : 2004. 9. 7.) 
Cho et al. ; Estimating Daily Milk Yield

Averaged error in $\mathrm{kg}$ Averaged error in $\mathrm{kg}$

Lactation stage in months

Lactation stage in months

Averaged error in $\mathrm{kg}$

Averaged error in $\mathrm{kg}$

Lactation stage in months

Lactation stage in months 